\title{
Copepod community growth rates in relation to body size, temperature, and food availability in the East China Sea: a test of metabolic theory of ecology
}

\author{
K. Y. Lin ${ }^{1}$, A. R. Sastri ${ }^{2}$, G. C. Gong ${ }^{3,4,5}$, and C. H. Hsieh ${ }^{1,6}$ \\ ${ }^{1}$ Institute of Oceanography, National Taiwan University, No. 1, Sec. 4, Roosevelt Road, Taipei, 10617, Taiwan \\ ${ }^{2}$ Department of Biological Sciences, Université du Québec à Montréal, Montreal H3C 3P8, Canada \\ ${ }^{3}$ Institute of Marine Environmental Chemistry and Ecology, National Taiwan Ocean University, No. 2 Pei-Ning Road, \\ Keelung, 20224, Taiwan \\ ${ }^{4}$ Center of Excellence for Marine Bioenvironment and Biotechnology, National Taiwan Ocean University, Keelung, \\ 20224, Taiwan \\ ${ }^{5}$ Taiwan Ocean Research Institute, National Applied Research Laboratories, Kaoshiung, 852, Taiwan \\ ${ }^{6}$ Institute of Ecology and Evolutionary Biology, National Taiwan University, No. 1, Sec. 4, Roosevelt Road, Taipei, \\ 10617, Taiwan
}

Correspondence to: C. H. Hsieh (chsieh@ntu.edu.tw)

Received: 26 October 2012 - Published in Biogeosciences Discuss.: 16 November 2012

Revised: 7 February 2013 - Accepted: 23 February 2013 - Published: 20 March 2013

\begin{abstract}
Zooplankton play an essential role in marine food webs, and understanding how community-level growth rates of zooplankton vary in the field is critical for predicting how marine ecosystem function may vary in the face of environmental changes. Here, we used the artificial cohort method to examine the effects of temperature, body size, and chlorophyll concentration (a proxy for food) on weight-specific growth rates for copepod communities in the East China Sea. Specifically, we tested the hypothesis that copepod community growth rates can be described by the metabolic theory of ecology (MTE), linking spatio-temporal variation of copepod growth rate with temperature and their body size. Our results generally agree with predictions made by the MTE and demonstrate that weight-specific growth rates of copepod communities in our study area are positively related with temperature and negatively related to body size. However, the regression coefficients of body size do not approach the theoretical predictions. Furthermore, we find that the deviation from the MTE predictions may be partly attributed to the effect of food availability (which is not explicitly accounted for by the MTE). In addition, significant difference in the coefficients of temperature and body size exists among taxonomic groups. Our results suggest that considering the ef-
\end{abstract}

fects of food limitation and taxonomy is necessary to better understand copepod growth rates under in situ conditions, and such effects on the MTE-based predictions need further investigation.

\section{Introduction}

Copepods represent 55-95\% of the total mesozooplankton abundance in marine pelagic systems (Longhurst, 1985). This group exerts considerable grazing impacts on singlecelled organisms (i.e., phytoplankton and microzooplankton; Webber and Roff, 1995) and represents the principal prey for larval fishes and other marine planktivores (Turner, 2004). Contrary to the assumption that large-bodied copepods dominate community grazing, several studies have demonstrated that smaller species (as well as early developmental stages of large species) have the potential to exert a greater grazing impact than larger animals by virtue of their greater abundance (e.g., Turner and Roff, 1993; Atkinson, 1996; Merrell and Stoecker, 1998). However, the ecology of small species has often been overlooked due to the coarse mesh size used in plankton nets (reviewed by Turner, 2004). This is especially 
the case for tropical and subtropical waters where small copepod species often dominate the zooplankton community biomass (e.g., McKinnon and Duggan, 2003). Therefore, empirical studies of specific properties of small copepods such as variation of productivity may help clarify the relative functional importance of this group in marine ecosystems.

Growth of organisms represents one of the most important trophodynamic processes in marine ecosystems (Kiørboe, 1997). Multiple methods for measuring copepod growth rates have been developed and applied at sea (e.g., Poulet et al., 1995; see Runge and Roff, 2000 for review). The artificial cohort method, developed by Kimmerer and McKinnon (1987), assumes that growth is logarithmic linear with time and represents one of the most well-studied and applied techniques for measuring copepod weight-specific growth rates in the field (e.g., Hopcroft et al., 1998; McKinnon and Duggan, 2003; Kobari et al., 2007). In practice, the approach relies on the creation and incubation of artificial cohorts consisting of selected developmental stages or size fractions (e.g., McKinnon and Duggan, 2003).

Understanding and interpreting the relative influence of multiple factors affecting in situ growth rates of zooplankton remains a central goal for plankton ecologists. Previous studies have suggested that food is an important determinant of copepod growth rates (e.g., Mullin and Brook, 1970). Two other factors commonly linked to variation in growth rates are temperature and body size (e.g., Hirst and Lampitt, 1998). According to the metabolic theory of ecology (MTE; Brown et al., 2004), weight-specific growth rate $(g)$ can be expressed as a function of temperature $(T)$ and body mass $(M)$ :

$g \propto \exp \left(-\frac{E}{k_{\mathrm{B}} T}\right) \times M^{-0.25}$

where $E$ is an enzyme-catalyzed activation energy for the biochemical reactions of metabolism, and $k_{\mathrm{B}}$ is the Boltzmann constant $\left(8.62 \times 10^{-5} \mathrm{eV} \mathrm{K}^{-1}\right)$. Given this relationship, the MTE predicts growth rates to vary in a negative manner with body size and a positive manner with temperature. Indeed, the important influence of temperature on copepod growth rates was noted early by Miller et al. (1977) and McLaren (1978). Many studies have since demonstrated that the growth rate is positively related to temperature in the field and laboratory (e.g., Landry, 1976; Vidal, 1980; Uye, 1991); however, some studies found a negative relationship between growth rate and temperature (e.g., Hirst and Bunker, 2003; Kobari et al., 2007). In addition to temperature, the vast majority of studies have also found growth rates to slow with increasing copepod body size (e.g., Paffenhöfer, 1976; Atkinson, 1994; Webber and Roff, 1995; Hopcroft and Roff, 1998; McKinnon and Duggan, 2003; Kingsolver and Huey, 2008); however, some notable exceptions also exist (Harris and Paffenhöfer, 1976; Paffenhöfer and Harris, 1976). Empirical functions have been developed to relate variation of growth rates to variation in temperature, body size, and phytoplankton biomass (e.g., Huntley and Lopez,
1992; Hirst and Sheader, 1997; Hirst and Lampitt, 1998; Hirst and Bunker, 2003).

While temperature, body size, and food availability have been demonstrated to have significant effects on copepod growth, these effects may vary among developmental stages and phylogenetic groups. For example, numerous studies have demonstrated that nauplii, copepodites, and adults respond differentially to food availability, i.e., growth rate of older development stages tend to be more sensitive to foodlimitation (e.g., Vidal, 1980; Berggreen et al., 1988; Richardson and Verheye, 1999; Finlay and Roff, 2006; Leandro et al., 2006). In addition, different developmental stages of copepods preferentially utilize different size ranges of food (Berggreen et al., 1988; Calbet et al., 2000; Conover, 1966; Reinfelder and Fisher, 1991; Bestikepe and Dam, 2002). Moreover, feeding habits vary among copepod species (e.g., Turner, 2004; Uye, 1994; as illustrated in Table A1). In addition to stage and taxon-specific food selectivity, the effects of temperature also vary among developmental stages. For example, naupliar growth rates were found to be more sensitive to temperature than those of copepodites and adults (McKinnon and Duggan, 2003). Another key difference occurs when considering different spawning types of copepods, i.e., broadcast spawners versus sac spawners, which respond differentially to temperature and body size effects (Hirst and Bunker, 2003). Therefore, species life history and/or developmental stage should be taken into consideration when estimating and attempting to relate variation of growth rate to the environment.

Here, we studied copepod community growth rates in the East China Sea. The relationships between the abundance, distribution, and feeding ecology of copepods to variation in their environment have been widely investigated in the seas surrounding Taiwan (e.g., Lan et al., 2008; Okazaki et al., 2008; Chen et al., 2010). However, very few studies have measured growth or production rates in order to infer community dynamics in this important marine ecosystem. For example, some studies have implied variation of growth rates by modeling the effect of temperature and chlorophyll $a$ concentration (Wang et al., 2007) or based on fecal pellet production (Wang and Fan, 1997). Here, we directly measured growth rates by employing the artificial cohort method on two size fractions which targeted copepod nauplii and copepodites. Our primary objective was to identify the dominant environmental factors influencing growth rates of copepod communities in the East China Sea. Specifically, we test the hypothesis that copepod community growth rates in our study area can be described by the MTE. 


\section{Materials and methods}

\subsection{Sampling}

All sampling and incubations were carried out aboard $\mathrm{R} / \mathrm{V}$ Ocean Researcher I and R/V Ocean Researcher II from March 2009 to November 2011 (Table B1 in Supplement). Stations were located in the East China Sea and the western Pacific area near Taiwan (Fig. 1). Note that because we were able to conduct experiments multiple times on separate occasions at certain stations, we refer to the stations separately by the numbers listed in Table B1 unless Fig. 1 is specified. Copepod weight-specific growth rate determinations (see "Artificial cohort method" below) were carried out at 31 stations.

Environmental data (e.g., depth-specific temperature and salinity) were obtained using a Seabird CTD-General Oceanic Rosette equipped with $20 \mathrm{~L}$ Go-Flo bottles. Incubation temperatures were measured periodically during incubations or taken from CTD measurements of sea surface temperature (SST) if the former measurements were lacking (because incubations were conducted in tanks circulated with surface seawater; see Fig. C1 in Supplement and "Artificial cohort method" below). Chlorophyll $a$ concentration at $10 \mathrm{~m}$ (measurements following the method described in Gong et al., 2003) was used as a proxy for food availability.

\subsection{Artificial cohort method}

Copepod weight-specific growth rates were measured using the artificial cohort method (Kimmerer and McKinnon, 1987). Artificial cohorts were established by collecting animals and incubating only a very limited body-size range, as shown in Fig. C1. These artificial cohort size fractions were chosen to reflect the predominance of the small size classes which make up the mesozooplankton communities in the waters surrounding Taiwan. Thus, we used 50-80 $\mu \mathrm{m}$ and 100$150 \mu \mathrm{m}$ size fractions, similar to those used by McKinnon and Duggan (2003) for isolating nauplii and copepodites, respectively. Shipboard incubations for each size fraction were carried out using 3 replicate $20 \mathrm{~L}$ collapsible polyethylene cubitainers. Incubation seawater (and thus food) was collected from $10 \mathrm{~m}$ using $20 \mathrm{~L}$ Go-Flo bottles. This water was screened through $50 \mu \mathrm{m}$ mesh (in order to exclude mesozooplankton), and the cubitainers were filled to $\sim 90 \%$ capacity. Seawater accompanying the size-fractionated zooplankton made up the remaining volume of each $20 \mathrm{~L}$ cubitainer.

Live zooplankton (mainly copepods) were collected using two separate Norpac zooplankton nets $(50$ and $100 \mu \mathrm{m}$ mesh, and each with a ring diameter of $45 \mathrm{~cm}$ ). At each station, the nets were set to $10 \mathrm{~m}$ and allowed to drift with the ship for 5$10 \mathrm{~min}$. The contents of each net were carefully re-suspended in buckets filled with pre-screened incubation seawater. After gentle mixing, the contents of the $50 \mu \mathrm{m}$ net were reversefiltered through $80 \mu \mathrm{m}$ mesh and siphoned $(\sim 2 \mathrm{~L})$ into cu-

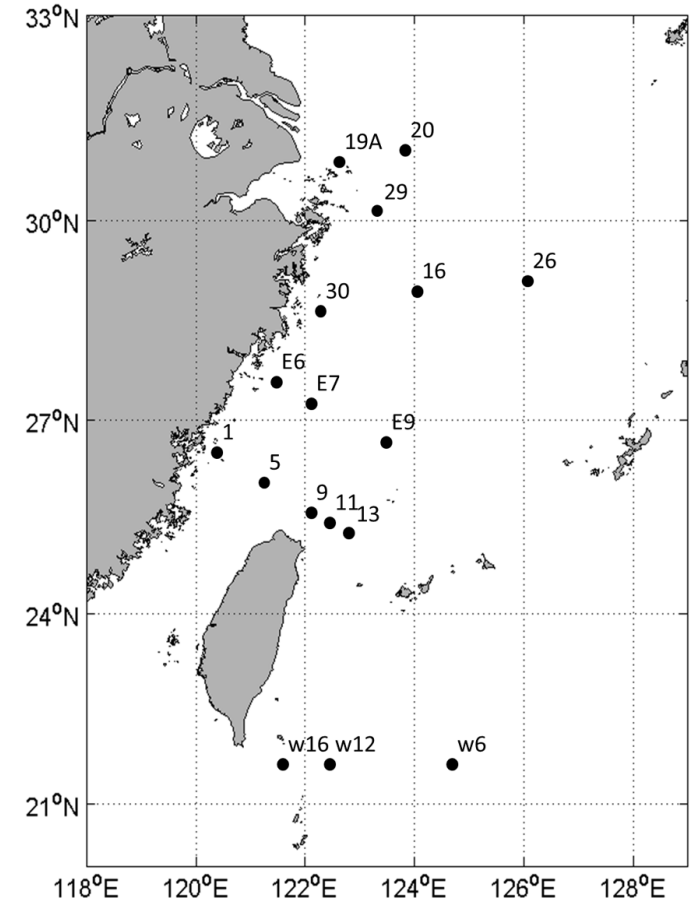

Fig. 1. Map showing experimental sites in the East China Sea and western Pacific Ocean.

bitainers for the $50-80 \mu \mathrm{m}$ artificial cohort incubations. Another subsample from the $80 \mu \mathrm{m}$ mesh reverse filtrate, representing the biomass distribution at the start of the incubation (i.e., time 0 ), was preserved using $5 \%$ formalin-buffered seawater. The process was repeated using the contents of the $100 \mu \mathrm{m}$ mesh net and filtered with a $150 \mu \mathrm{m}$ mesh to establish a $100-150 \mu \mathrm{m}$ artificial cohort. Animals were visually inspected prior to incubation to confirm that there was no mortality before incubations. All cubitainers were incubated in dark black tanks (about $200 \mathrm{~L}$ in volume) filled with circulating seawater pumped constantly from the surface during each cruise. We chose to incubate the $50-80 \mu \mathrm{m}$ size fraction for $24 \mathrm{~h}$ and $100-150 \mu \mathrm{m}$ size fraction for $48 \mathrm{~h}$ in order to allow sufficient time for measurable growth to occur. The environment in the cubitainers was assumed to be similar to in situ condition along the incubation, except that the tanks were always kept dark during incubation. Such a design aims to prevent growth of primary producers during incubation so that the total available food can be quantified using the initial food concentration. While ideally temporal variation of food concentration in the cubitainers should be measured periodically, we did not carry out such measurements in order to avoid disturbing the incubation. Any disturbance potentially creates undesired mortality. However, we do acknowledge that the duration of our incubations (specifically the $48 \mathrm{~h}$ incubation) may have led to differences in the types and quantities of food available to incubated animals relative to that in the water column. This incubation time represents a 
necessary trade-off between potential incubation effects and allowing sufficient time for growth to be measurable. At the conclusion of each of the incubations, the contents of each cubitainer were concentrated onto a $50 \mu \mathrm{m}$ mesh and animals were preserved with buffered $5 \%$ formalin seawater.

\subsection{Classification, enumeration, and growth rate estimation}

Preserved samples were identified and enumerated using a dissecting microscope, and images of $8 \times 10$ magnification were taken using a CCD camera (Olympus DP71 with the software analySIS LS Starter 2.6) mounted on the microscope. Here we followed the protocol of McKinnon and Duggan (2003) and limited our analysis to copepod morphotypes rather than individual species (e.g., Kimmerer and McKinnon, 1987; Liu and Hopcroft, 2006a, b; Kobari et al., 2007). In the 50-80 $\mu \mathrm{m}$ size fraction, our morphotypes were calanoid (Calanoida) and cyclopoid (Cyclopoida) nauplii. We occasionally found harpacticoid (Harpacticoida) nauplii in our incubations, and these animals were measured and enumerated when sufficiently abundant. In the 100$150 \mu \mathrm{m}$ size fraction, we measured, enumerated and identified calanoid, oithonid (Cyclopoida Oithonidae), harpacticoid, oncaeid (Poecilostomatoida Oncaeidae) and corycaeid (Poecilostomatoida Corycaeidae) copepodites in addition to calanoid and cyclopoid nauplii. As the development stages and life history of copepods should be considered when clarifying relationships between growth rate and its determinants, analyses were carried out separately for different size fractions $(50-80 \mu \mathrm{m}$ and $100-150 \mu \mathrm{m})$, for different spawning types (broadcasters and sac-spawners), and for all data as a whole. The broadcaster group includes calanoids (most of the calanoid species in our incubations were broadcast spawning groups, but we acknowledge some exceptions to this grouping), while the sac-spawner group includes all cyclopoids (including oithonid, oncaeid and corycaeid) and harpacticoids.

The prosome length and width of each individual was measured from digital images of copepods. Body size metrics for morphotypes of different shapes were calculated according to Svetlichny (1983):

wet weight $(\mathrm{WW})=K_{\mathrm{c}} \times$ prosomal length $\times$ width $^{2}$,

where $K_{\mathrm{c}}$ is a constant, 0.6 for calanoids and 0.705 for cyclopoids (McKinnon and Duggan, 2003), and an average value of 0.65 for groups where conversion factors were not available. A conversion factor of $0.135 \times 0.42$ was used to convert wet weight to carbon weight, i.e.,

dry weight $(\mathrm{DW})=0.135 \times \mathrm{WW} \quad($ Postel et al., 2000) and

carbon weight $(\mathrm{W})=0.42 \times \mathrm{DW} \quad($ Beers, 1966).
Assuming exponential growth (e.g., Kimmerer et al., 2007), the weight-specific growth rate $(g)$ was calculated as:

$g=\ln \left(\frac{W_{\mathrm{T}}}{W_{0}}\right) / T$,

where $W_{0}$ is the carbon biomass of copepods at the beginning of incubation, $W_{\mathrm{T}}$ is the carbon biomass at the end of incubation, and $T$ represents the incubation time of 24 and $48 \mathrm{~h}$ for the $50-80$ and $100-150 \mu \mathrm{m}$ size fractions, respectively. The representative carbon biomass for each copepod assemblage (i.e., $W_{0}$ and $W_{\mathrm{T}}$ ) was estimated by multiple-peak consideration (Lin et al., 2013) (see brief description in Supplement D) instead of average carbon biomass; in other words, the modes of the biomass values were considered when determining the representative biomass for each assembly. Weight-specific growth rates were estimated from the average value of three replicates for each size fraction for each copepod taxon. Note that the sample for the $50-80 \mu \mathrm{m}$ size fraction for our Station 2 was missing; therefore, such information cannot be included in calculation and analysis.

\subsection{Data pretreatment}

The prerequisite in testing MTE is that no food limitation exists for the rate measurements. Thus, before comparison to the predictions of the MTE, we must first identify and then exclude food-limited growth rate estimates from the data set. As a compromise for assessing food concentration, we consider chlorophyll $a$ concentration with the Monod equation:

$g=\frac{g_{\max }[\mathrm{Chl}]}{K_{m}+[\mathrm{Chl}]}$

where $g$ is the measured weight-specific growth rate, $g_{\max }$ is maximum rate of $g$, [Chl] is the chlorophyll $a$ concentration, and $K_{m}$ is the chlorophyll $a$ concentration at which $g$ equals $g_{\max } / 2$. Through fitting the Monod function, we found no significant relationship between $g$ and [Chl]. However, to be more conservative and considering the scattering of the growth rate data, we also investigated the function

$\ln (g)=\frac{g_{\max }[\mathrm{Chl}]}{K_{m}+[\mathrm{Chl}]}$.

With this model fitting, we found a significant relationship $(p<0.05)$ between measured weight-specific growth rates and chlorophyll $a$ concentration only for the broadcast spawners but not other groups (Fig. 2). To remove the possibility of confounding effects of food limitation in testing MTE, growth rates measured at chlorophyll $a$ concentrations below $4 \times K_{m}\left(0.30 \mathrm{mg} \mathrm{L}^{-1}\right.$; defined as "food-limited") for the broadcaster group were eliminated from all following analyses (Fig. E1 in Supplement; 34 data points were eliminated). No positive linear relationship between $g$ and [Chl] was detected after elimination. Note that there might be some 

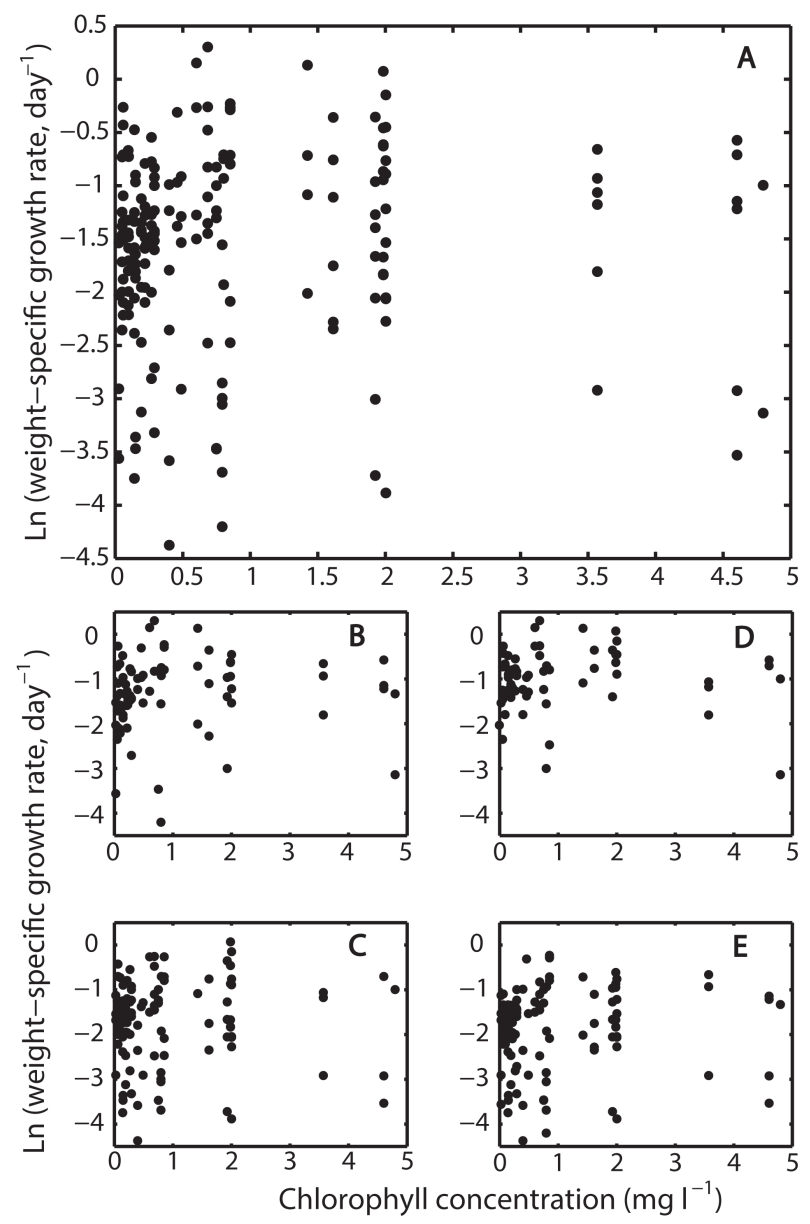

Fig. 2. Relationship between $\ln$ (weight-specific growth rate) and chlorophyll a concentration before exclusion of "food-limited" growth, for (A) all data as a whole, (B) broadcaster, (C) sacspawner, (D) 50-80 $\mu \mathrm{m}$, and (E) 100-150 $\mu \mathrm{m}$ groups. See the text for the definition of "food-limited" growth.

slow growth rates even when [Chl] is higher than $4 \times K_{m}$; these slow rates are presumably due to effects of other factors (e.g., temperature, body size). As a consequence, a total of 155 data points were retained for comparisons to MTEbased predictions.

\subsection{Testing metabolic theory of ecology}

To investigate whether the copepod community growth rates could be described by the MTE, weight-specific growth rates were fitted to the relationship proposed by the MTE (Brown et al., 2004) using the generalized linear model (GLM):

$\ln (g)=a_{0}+\frac{a_{1}}{T}+a_{2} \ln \left(W_{0}\right)$,

where the coefficient $a_{0}$ is the intercept, $a_{1}$ is the factor of activation energy associated with temperature, and $a_{2}$ is the allometric coefficient for body size. Here, the body size $\left(W_{0}\right)$ is measured as the carbon weight at beginning of incubation for each copepod assemblage. In addition, a 10-fold crossvalidation (Cudeck and Browne, 1983) was performed to evaluate the GLM for each group. That is, we randomly divided the data set into 10 subsamples, and used 9 subsamples to construct the GLM model and the remaining subsample to evaluate the model performance (based on prediction error). The same procedure was repeated 10 times to exhaust the 10 combinations, and the average error was calculated. Small prediction error is considered as good performance. In addition to the GLM, we independently analyzed our data in the form of "temperature-corrected weight-specific growth rate" in relation to body size (carbon weight, $W_{0}$ ) by ordinary least squares, major axis, and standardized major axis regressions:

$g^{\prime}=a_{0}^{\prime}+a_{1}^{\prime} \ln \left(W_{0}\right)$,

where $g^{\prime}=\ln (g)+\left(E / k_{\mathrm{B}}\right) T^{-1}, a_{0}^{\prime}$ is the intercept and $a_{1}^{\prime}$ is the allometric coefficient for body size.

\subsection{Testing effects of food limitation}

We attempted to remove food-limited growth rate estimates from our analyses by eliminating the growth rate estimates for broadcast spawners growing at chlorophyll $a$ concentration below $4 \times K_{m}$. However, we are not completely confident that this approach effectively identified food-limited rate estimates. To further explore the issue of food limitation, two additional analyses were carried out. First, we calculated the residuals from regression, Eq. (6), and investigated whether a linear relationship exists between the residuals and chlorophyll $a$ concentration. In addition, we investigated whether a relationship described by the Monod equation exists between the residuals and chlorophyll $a$ concentration. Secondly, we took an alternative approach. Instead of taking the residuals of regression, Eq. (6), we analyzed weight-specific growth rate in relation to temperature, body size and chlorophyll $a$ concentration in a multivariate fashion. Specifically, four models were constructed:

Model 0 (no food effect) :

$g=a_{0} \times \exp \left(\frac{a_{1}}{T}\right) \times W_{0}^{a_{2}} ;$

Model 1 (linear dependence on food) :

$g=a_{0} \times \exp \left(\frac{a_{1}}{T}\right) \times W_{0}^{a_{2}}+a_{3}[\mathrm{Chl}] ;$

Model 2 (Monod equation) :

$g=a_{0} \times \exp \left(\frac{a_{1}}{T}\right) \times W_{0}^{a_{2}}+\frac{a_{3}[\mathrm{Chl}]}{a_{4}+[\mathrm{Chl}]} ; \quad$ and

Model 3 (logistic form) :

$g=a_{0} \times \exp \left(\frac{a_{1}}{T}\right) \times W_{0}^{a_{2}}+\frac{a_{3} \times \exp ([\mathrm{Chl}])}{\exp ([\mathrm{Chl}])+a_{4}}$ 


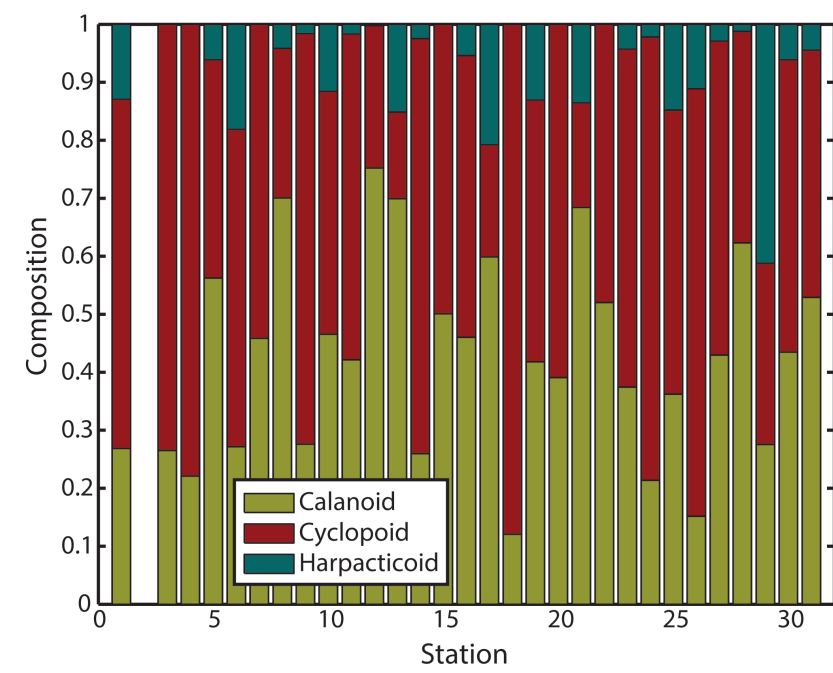

Fig. 3. Taxonomic composition of copepods incubated in our size fraction $50-80 \mu \mathrm{m}$ at each station. Taxa are denoted by different colors; stations are numbered according to Table B1. Note that the data of the $50-80 \mu \mathrm{m}$ size fraction for station 2 are missing.

We considered two data sets (i.e., the values of "foodlimited" growth rate were excluded or included) in analysis.

\subsection{Spatio-temporal variation and the effect of taxonomy on growth rate}

In addition to size and temperature, the effects of spatial and seasonal variation and taxonomy on growth rates of copepods were also examined. Spatial groups were defined on the basis of environmental data using $K$ means clustering (Seber and Hoboken, 1984). Only surface salinity from CTD and chlorophyll $a$ concentration data were used in the $K$ means analysis in order to contrast the coastal and offshore area. Four groups were determined and characterized by "high salinity, low chlorophyll (group A)", "high salinity, high chlorophyll (group B)", "low salinity, low chlorophyll (group C)" and "low salinity, high chlorophyll (group D)" (Table B1). The definition of seasons follows regional climatology (Table B1). The taxonomic groups were defined according to their morphotypes (defined in Sect. 2.3). We investigated the spatial, temporal, and taxonomic effects on growth rate using GLM with a stepwise selection procedure. We consider the following equation:

$$
\begin{aligned}
\ln (g)= & \frac{\beta_{1}}{T}+\beta_{2} \ln \left(W_{0}\right)+\beta_{3} \times \operatorname{taxa}+\beta_{4} \times \text { spawn } \\
& +\beta_{5} \times \text { season }+\beta_{6} \times \text { space }+\varepsilon,
\end{aligned}
$$

where $\beta_{1}, \beta_{2}, \beta_{3}, \beta_{4}, \beta_{5}$, and $\beta_{6}$ represent coefficients of the following variables: $T$ is temperature $(K) ; W_{0}$ is body size (carbon weight, $\mu \mathrm{g}$ ); taxa represents the categorical variable of taxa (including 7 taxa in 100-150 $\mu \mathrm{m}$ and 3 taxa 50-80 $\mu \mathrm{m}$ size fraction); "spawn" represents the categorical variable of spawning type (broadcaster and sac-spawner); "season" rep-
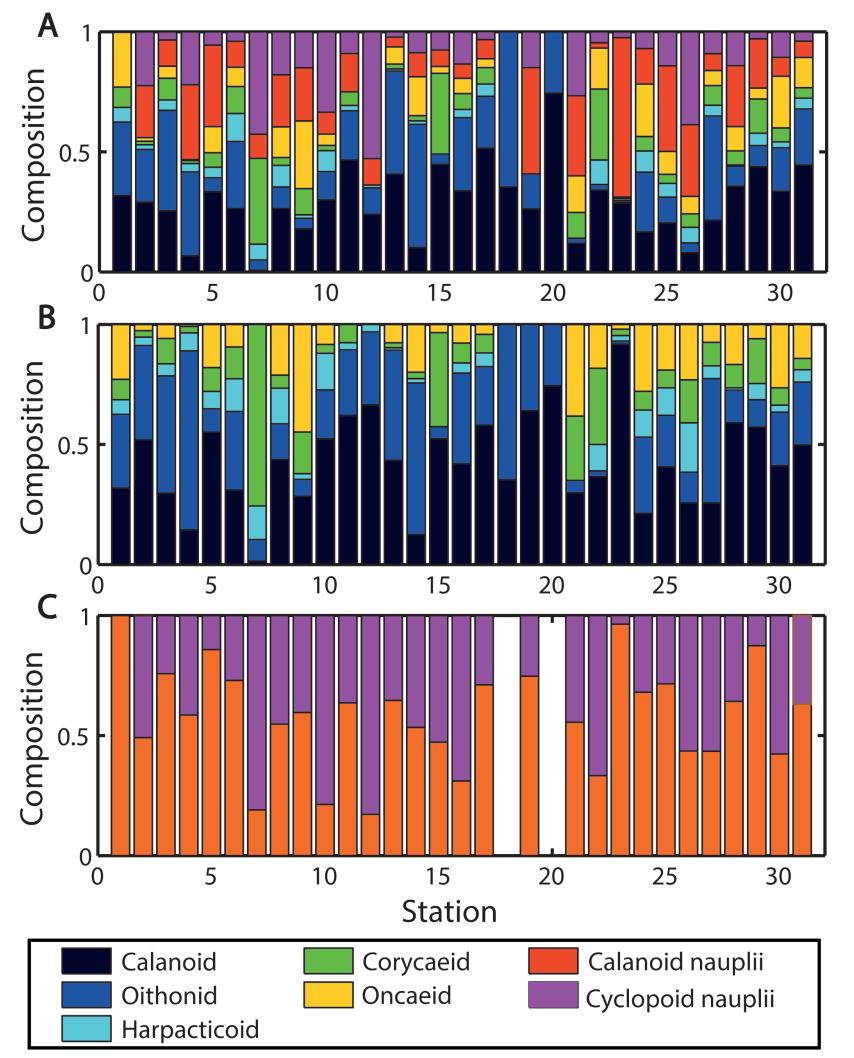

Fig. 4. Taxonomic composition of copepods incubated in our size fraction 100-150 $\mu \mathrm{m}$ at each station, for (A) all taxa included, (B) copepodites only, and (C) nauplii only. Taxa are denoted by different colors; stations are numbered according to Table B1. Note that there were no nauplii found in the $100-150 \mu \mathrm{m}$ size fraction in station 18 and 20.

resents the categorical variable of season (spring, summer, and winter); "space" represents the categorical variable of four $K$ means groups; and $\varepsilon$ is the error term. The threshold for variable add-in is $p=0.05$, and the threshold for variable elimination is $p=0.10$. Post hoc pairwise comparisons were carried out if any of the categorical variables were deemed to be significant.

\section{Results}

\subsection{Taxonomic composition}

Calanoid and cyclopoid nauplii dominated the abundance (average $42.36 \%$ and $50.47 \%$, respectively) in the $50-80 \mu \mathrm{m}$ size fraction (Fig. 3), while harpacticoid nauplii were only occasionally found in our incubations (average $7.17 \%$ ). On average, our $100-150 \mu \mathrm{m}$ size fraction was made up of $30.34 \%$ nauplii and $69.66 \%$ copepodites (Fig. 4). Calanoid and cyclopoid nauplii were similar in number. Calanoid copepodites dominated the $100-150 \mu \mathrm{m}$ size fraction for most stations, but their numerical dominance was sometimes 
Table 1. Regression coefficients of temperature and body size in relation to weight-specific growth rate, according to the function $\ln (g)=a_{0}+$ $\frac{a_{1}}{T}+a_{2} \ln \left(W_{0}\right)$ for different groups and all data as a whole. Values in parentheses: bootstrap estimates of standard error of coefficients; $g$ : weight-specific growth rate $\left(\right.$ day $\left.^{-1}\right) ; W_{0}$ : body size (carbon weight, $\left.\mu \mathrm{g}\right) ; T$ : temperature $(\mathrm{K}) ; E$ : activation energy $(\mathrm{eV}), E=-a_{1} \times k_{B} ;$ and $k_{B}$ : Boltzmann's constant $\left(8.62 \times 10^{-5} \mathrm{eV} \mathrm{K}^{-1}\right)$. Expected value represents the theoretical value according to MTE (Gillooly et al, 2001; Brown et al., 2004); MSE of cross-validation: mean squared error calculated from 10-fold cross-validation analysis.

\begin{tabular}{|c|c|c|c|c|c|c|c|c|}
\hline & $\begin{array}{r}a_{0} \\
\text { (growth } \\
\text { constant) }\end{array}$ & $\begin{array}{r}a_{1} \times 10^{-3} \\
\text { (temperature } \\
\text { constant) }\end{array}$ & $\begin{array}{r}E \\
\text { (activation } \\
\text { energy) }\end{array}$ & $\begin{array}{r}a_{2} \\
\text { (size } \\
\text { coefficient) }\end{array}$ & $r^{2}$ & $\begin{array}{r}p \\
\text { value }\end{array}$ & $\begin{array}{r}\text { Sample } \\
\text { size }\end{array}$ & $\begin{array}{r}\text { MSE } \\
\text { of cross- } \\
\text { validation }\end{array}$ \\
\hline $50-80 \mu \mathrm{m}$ & $6.90( \pm 11.94)$ & $-3.36( \pm 3.60)$ & $0.29( \pm 0.31)$ & $-0.88( \pm 0.34)$ & 0.15 & 0.02 & 53 & 0.55 \\
\hline $100-150 \mu \mathrm{m}$ & $18.99( \pm 8.55)$ & $-6.38( \pm 2.55)$ & $0.55( \pm 0.22)$ & $-0.32( \pm 0.21)$ & 0.08 & 0.01 & 102 & 0.57 \\
\hline Broadcaster & $24.15( \pm 16.42)$ & $-7.77( \pm 4.87)$ & $0.67( \pm 0.42)$ & $-0.27( \pm 0.18)$ & 0.17 & 0.03 & 42 & 0.80 \\
\hline Sac-spawner & $13.25( \pm 7.39)$ & $-4.87( \pm 2.20)$ & $0.42( \pm 0.19)$ & $-0.56( \pm 0.07)$ & 0.31 & $<0.01$ & 113 & 0.44 \\
\hline All & $15.61( \pm 6.93)$ & $-5.57( \pm 2.09)$ & $0.48( \pm 0.18)$ & $-0.51( \pm 0.07)$ & 0.26 & $<0.01$ & 155 & 0.43 \\
\hline Expected value & & & $0.6-0.7$ & -0.25 & & & & \\
\hline
\end{tabular}

replaced by other taxa (e.g., corycaeids at Station 7; see Fig. 4). We found no significant difference in the overall taxonomic composition in incubations among stations for both size fractions (Kruskal-Wallis one-way ANOVA: the 50$80 \mu \mathrm{m}$ fraction: $\chi^{2}=0.44, p>0.99$, the $100-150 \mu \mathrm{m}$ fraction: $\left.\chi^{2}=13.69, p>0.99\right)$.

\subsection{Weight-specific growth rate in relation to temperature, body size and chlorophyll $a$ concentration}

Weight-specific growth rates ranged from 0.04 to 1.35 in the $50-80 \mu \mathrm{m}$ size fraction, and 0.01 to 0.79 in the 100 $150 \mu \mathrm{m}$ size fraction (Fig. 5). High growth rates were possible and these rates could be attributed to adequate environments for copepods to grow rapidly (e.g., high temperature accompanied with ample food supply) and are also observed in some studies in warm waters (e.g. growth rate: $0.10-1.43$ in the area with temperature of $28^{\circ} \mathrm{C}$, Hopcropt and Roff, 1988). Weight-specific growth rates were positively related to temperature and negatively to body size (Table 1). The range of temperature coefficients overlapped with the values predicted by MTE $(E=0.6-0.7 \mathrm{eV}$; Gillooly et al., 2001), while the coefficient for body size did not approach the predicted value $(-0.25)$. Similar patterns emerged when we considered specific groups (i.e., different size fractions and spawning types), and the mean squared errors (MSEs) of 10 -fold cross-validation were also similar among groups. Nevertheless, the ranges of body size coefficients in the 100$150 \mu \mathrm{m}$ and broadcaster groups overlapped with the theoretical value, -0.25 . The coefficients for the small size fractions $(50-80 \mu \mathrm{m})$ were smaller with respect to temperature and more negative with respect to size than that of the large size fractions $(100-150 \mu \mathrm{m})$. The sac-spawners also had a smaller temperature coefficient and a more negative size coefficient than that of the broadcaster group. Considering the regression of "temperature-corrected weight-specific growth

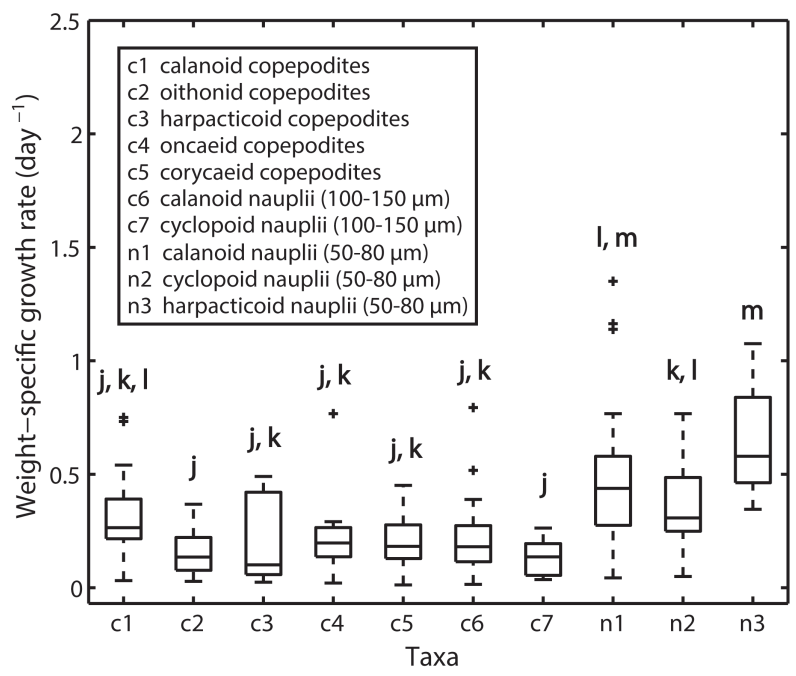

Fig. 5. Weight-specific growth rate $\left(\right.$ day $\left.^{-1}\right)$ of each taxon of copepods. The boxplots for each taxon indicate the values of medians, 25th and 75th percentiles (box ranges), $95 \%$ confidence intervals (whiskers), and outliers (crosses). The alphabetical symbols above the boxplots (i.e., j, k, 1, and $\mathrm{m}$ ) indicate the groups by post hoc pairwise comparison; i.e., the groups with the same symbols represent no significant difference in their growth rates. Note that the grouping was only for comparison among the ten taxa, distinct from the five groups (i.e., all data as a whole, broadcaster, sac-spawner, $50-80 \mu \mathrm{m}$, and $100-150 \mu \mathrm{m})$ we used in analysis.

rate" and "body size", the size coefficients of $100-150 \mu \mathrm{m}$ and broadcaster groups still overlapped with the theoretical value $(-0.25)$ (Table 5). There was an improvement in the size coefficients of the $50-80 \mu \mathrm{m}$ group (from $-0.96 \pm 0.32$ to $-0.39 \pm 0.14$ ), while the size coefficients estimated for the other groups were still deviated from -0.25 (Table 5).

The linear or Monod equation as a functional response between residuals from regression Eq. (8) and chlorophyll $a$ concentrations was not significant when considering growth 

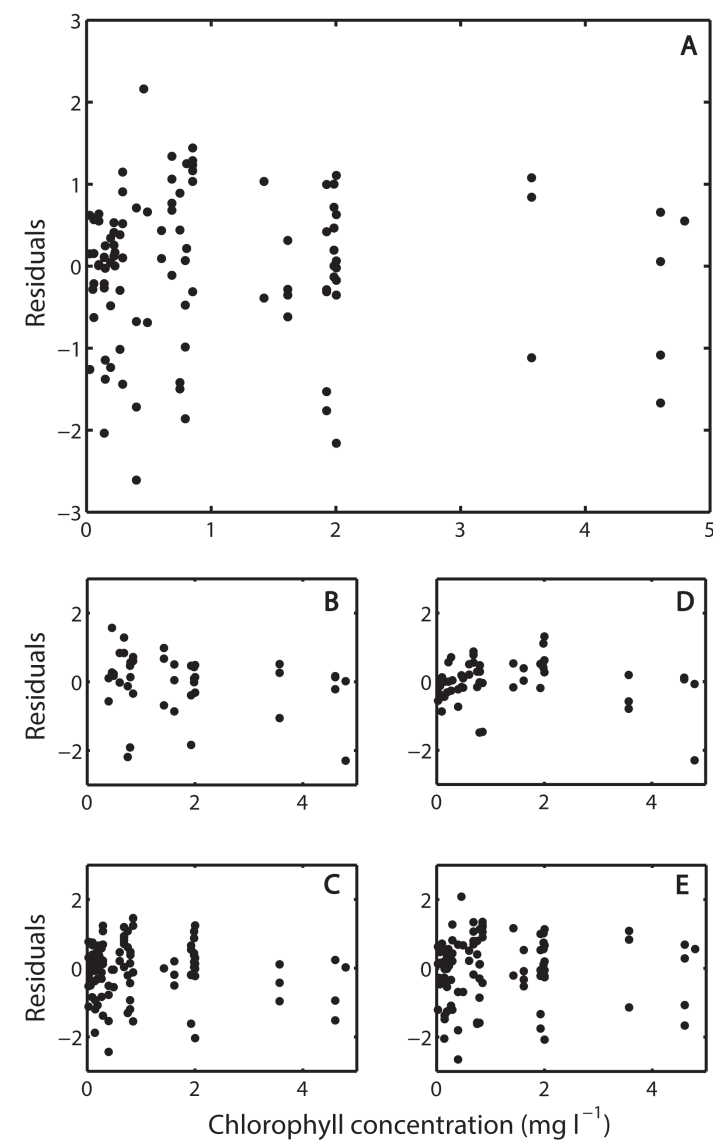

Fig. 6. Relationship between the residuals (growth rates deviating from the MTE prediction) and chlorophyll $a$ concentrations for (A) all data as a whole, (B) broadcaster, (C) sac-spawner, (D) 50-80 $\mu \mathrm{m}$, and (E) 100-150 $\mu \mathrm{m}$ group.

rates for the groups of all data as a whole, different size fractions, or spawning types (Fig. 6, $r<0.1, p>0.05$ in all five panels). We also analyzed weight-specific growth rate in relation to temperature, body size and chlorophyll $a$ concentration in a multivariate fashion. Among the four models, the Monod function or logistic form of chlorophyll $a$ concentrations combined with temperature and size effects best (lowest AIC) explains the variation of growth rate (Table 2). This result was qualitatively similar when we used the data set including potential "food-limited" growth values (Table 3).

\subsection{Seasonal and spatial variation and effects of taxonomy}

The results of the multivariate stepwise analysis of model Eq. (8) indicate that the factors determining the variation of growth rate only include temperature, body size, and taxa (Table 4). Other factors (i.e., spawn, season, and space) were not significant $(p>0.05)$. With respect to the taxonomic effect, pairwise comparison was made and the grouping is shown in Fig. 5 (i.e., the groups with the same alphabet sym-

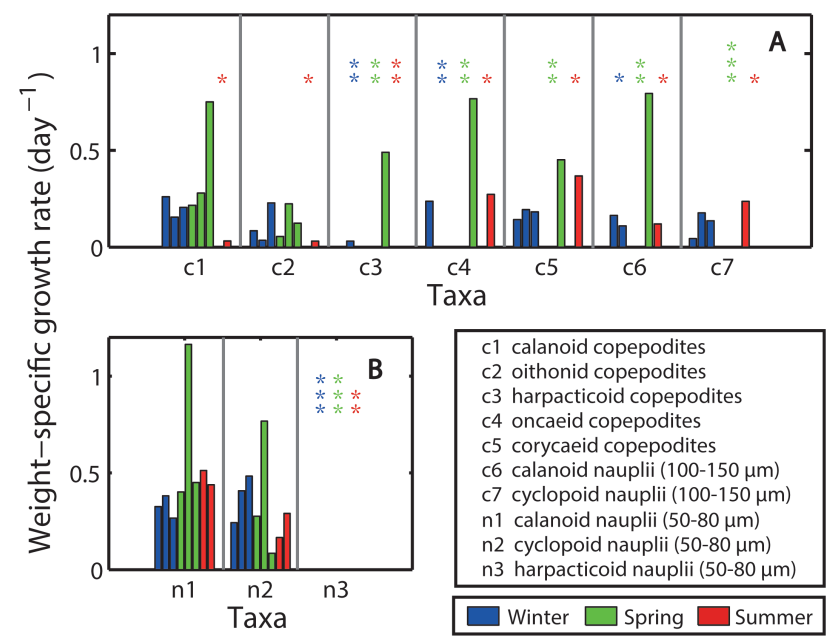

Fig. 7. Weight-specific growth rates of (A) taxa in the 100-150 $\mu \mathrm{m}$ size fraction and (B) taxa in the 50-80 $\mu \mathrm{m}$ size fraction in spring, summer and winter. Only data from station 9 in Fig. 1 were plotted. At some stations, the taxa were scarce in number $(<30$ as described in Supplement E); therefore, the growth rates were not calculated and not presented in this figure. For each taxon (separated by gray lines), asterisks indicate where there were no available growth rates (the number of asterisks indicates the number of missing values in corresponding seasons).

bols indicate no significant difference in their growth rates). In addition, we were able to measure growth rates at a single station (station 9 in Fig. 1) on 8 separate occasions and found that growth rates of calanoid nauplii decreased but that of cyclopoid nauplii increased in winter (Fig. 7). Also, the variation of growth rates for calanoids (standard deviation of nauplii: 0.28 ; copepodite: 0.23 ) were higher than that of cyclopoids (standard deviation of nauplii: 0.21 ; copepodite: 0.08; Fig. 7).

\section{Discussion}

Here for the first time, we measured the in situ growth rates of copepod communities in the East China Sea. Our objective was to explore the effects of temperature, body size, and food concentration on in situ weight-specific growth rate. We also tested the MTE-based predictions of growth rate against our direct measurements and examined the relative influence of food limitation on copepod productivity in our study area.

\subsection{Test of the MTE - temperature effects}

Overall, we found a significant correlation between weightspecific growth rate versus temperature and body size as described by Eq. (8), with the MSE of cross-validation similar among groups (Table 1). In keeping with some general expectations (e.g., Mullin and Brook, 1970; Huntley and Lopez, 1992), weight-specific growth rate was positively 
Table 2. Results of nonlinear models that consider temperature, body size and food (chlorophyll $a$ concentration) effects. The "foodlimited" growth values were excluded from the data set. Values in parentheses: standard error of coefficients; $g$ : weight-specific growth rate $\left(\right.$ day $\left.^{-1}\right) ; W_{0}$ : body size (carbon weight, $\left.\mu \mathrm{g}\right) ; T$ : temperature $(\mathrm{K}) ; E$ : activation energy $(\mathrm{eV}), E=-a_{1} \times k_{B} ; k_{B}$ : Boltzmann's constant $\left(8.62 \times 10^{-5} \mathrm{eV} \mathrm{K}^{-1}\right)$; and [Chl] : concentration of chlorophyll $a$ concentration $\left(\mathrm{mg} \mathrm{L}^{-1}\right)$.

\begin{tabular}{|c|c|c|c|c|c|c|}
\hline $\begin{array}{l}a_{0} \times 10^{4} \\
\text { (growth } \\
\text { constant) }\end{array}$ & $\begin{array}{r}a_{1} \times 10^{-3} \\
\text { (temperature } \\
\text { constant) }\end{array}$ & $\begin{array}{r}E \\
\text { (activation } \\
\text { energy) }\end{array}$ & $\begin{array}{r}a_{2} \\
\text { (size } \\
\text { coefficient) }\end{array}$ & $\begin{array}{r}a_{3} \\
\text { (constant of } \\
\text { functional } \\
\text { response) }\end{array}$ & $\begin{array}{r}a_{4} \\
\text { (constant of } \\
\text { functional } \\
\text { response) }\end{array}$ & AIC \\
\hline \multicolumn{7}{|c|}{ Model 0 (no food effect): $g=a_{0} \times \exp \left(\frac{a_{1}}{T}\right) \times W_{0}^{a_{2}}$} \\
\hline $6.09( \pm 61.00)$ & $-5.22( \pm 1.28)$ & $0.45( \pm 0.11)$ & $-0.35( \pm 0.26)$ & & & -29.53 \\
\hline \multicolumn{7}{|c|}{ Model 1 (linear dependence on food): $g=a_{0} \times \exp \left(\frac{a_{1}}{T}\right) \times W_{0}^{a_{2}}+a_{3}[\mathrm{Chl}]$} \\
\hline $2.71( \pm 28.97)$ & $-5.45( \pm 1.39)$ & $0.47( \pm 0.12)$ & $-0.33( \pm 0.27)$ & $0.02( \pm 0.03)$ & & -28.22 \\
\hline \multicolumn{7}{|c|}{ Model 2 (Monod equation): $g=a_{0} \times \exp \left(\frac{a_{1}}{T}\right) \times W_{0}^{a_{2}}+\frac{a_{3}[\mathrm{Chl}]}{a_{4}+[\mathrm{Chl}]}$} \\
\hline $23.69( \pm 705.2)$ & $-29.81( \pm 9.40)$ & $2.57( \pm 0.81)$ & $-0.44( \pm 0.71)$ & $0.31( \pm 0.06)$ & $0.09( \pm 0.09)$ & -56.17 \\
\hline \multicolumn{7}{|c|}{ Model 3 (Logistic form): $g=a_{0} \times \exp \left(\frac{a_{1}}{T}\right) \times W_{0}^{a_{2}}+\frac{a_{3} \times \exp ([\mathrm{Ch} 1])}{\exp ([\mathrm{Chl}])+a_{4}}$} \\
\hline $0.001( \pm 0.018)$ & $-31.32( \pm 9.86)$ & $2.70( \pm 0.85)$ & $-0.38( \pm 0.73)$ & $0.33( \pm 0.08)$ & $0.56( \pm 0.57)$ & -56.41 \\
\hline
\end{tabular}

Table 3. Results of nonlinear models that consider temperature, body size and different food (chlorophyll $a$ concentration) effects. The "foodlimited" growth values were included. Values in parentheses: standard error of coefficients; $g$ : weight-specific growth rate $\left(\right.$ day $\left.{ }^{-1}\right) ; W_{0}$ : body size (carbon weight, $\mu \mathrm{g}) ; T$ : temperature $(\mathrm{K}) ; E$ : activation energy $(\mathrm{eV}), E=-a_{1} \times k_{B} ; k_{B}$ : Boltzmann's constant $\left(8.62 \times 10^{-5} \mathrm{eV} \mathrm{K}^{-1}\right)$; and [Chl]: concentration of chlorophyll $a$ concentration $\left(\mathrm{mg} \mathrm{L}^{-1}\right)$.

\begin{tabular}{|c|c|c|c|c|c|c|}
\hline $\begin{array}{l}a_{0} \times 10^{4} \\
\text { (growth } \\
\text { constant) }\end{array}$ & $\begin{array}{r}a_{1} \times 10^{-3} \\
\text { (temperature } \\
\text { constant) }\end{array}$ & $\begin{array}{r}E \\
\text { (activation } \\
\text { energy) }\end{array}$ & $\begin{array}{r}a_{2} \\
(\text { size } \\
\text { coefficient })\end{array}$ & $\begin{array}{r}a_{3} \\
\text { (constant of } \\
\text { functional } \\
\text { response) }\end{array}$ & $\begin{array}{r}a_{4} \\
\text { (constant of } \\
\text { functional } \\
\text { response) }\end{array}$ & AIC \\
\hline \multicolumn{7}{|c|}{ Model 0 (no food effect): $g=a_{0} \times \exp \left(\frac{a_{1}}{T}\right) \times W_{0}^{a_{2}}$} \\
\hline $0.13( \pm 1.13)$ & $-5.45( \pm 1.16)$ & $0.47( \pm 0.10)$ & $-0.37( \pm 0.23)$ & & & -50.63 \\
\hline \multicolumn{7}{|c|}{ Model 1 (linear dependence on food): $g=a_{0} \times \exp \left(\frac{a_{1}}{T}\right) \times W_{0}^{a_{2}}+a_{3}[\mathrm{Chl}]$} \\
\hline $0.07( \pm 0.72)$ & $-5.92( \pm 1.28)$ & $0.51( \pm 0.11)$ & $-0.36( \pm 0.25)$ & $0.03( \pm 0.02)$ & & -49.79 \\
\hline \multicolumn{7}{|c|}{ Model 2 (Monod equation): $g=a_{0} \times \exp \left(\frac{a_{1}}{T}\right) \times W_{0}^{a_{2}}+\frac{a_{3}[\mathrm{Chl}]}{a_{4}+[\mathrm{Chl}]}$} \\
\hline $31.29( \pm 771.5)$ & $-19.26( \pm 8.35)$ & $1.66( \pm 0.72)$ & $-0.47( \pm 0.64)$ & $0.33( \pm 0.06)$ & $0.14( \pm 0.10)$ & -81.75 \\
\hline \multicolumn{7}{|c|}{ Model 3 (Logistic form): $g=a_{0} \times \exp \left(\frac{a_{1}}{T}\right) \times W_{0}^{a_{2}}+\frac{a_{3} \times \exp ([\mathrm{Chl}])}{\exp ([\mathrm{Chl}])+a_{4}}$} \\
\hline $0.000( \pm 0.001)$ & $-28.31( \pm 8.12)$ & $2.44( \pm 0.70)$ & $-0.40( \pm 0.58)$ & $0.33( \pm 0.07)$ & $0.64( \pm 0.50)$ & -83.95 \\
\hline
\end{tabular}

correlated with temperature. The estimated temperature coefficients (Table 1) overlapped the range predicted by the MTE (0.6-0.7 eV; Gillooly et al., 2001), but the average values were relatively low for most groups. There are at least two competing hypotheses in the debate over the pattern of temperature dependence: (1) universal temperature dependence (UTD; Gillooly et al., 2001) and (2) evolutionary trade-off hypothesis (ETO; Clarke, 2004). UTD predicts a similar temperature dependence of intra- and interspecies metabolic rates, while ETO predicts a steeper slope of temperature-rate relationship for intraspecies relative to interspecies compar- isons. Since the taxonomic level of our data set was coarse, it is difficult to ascribe patterns in our results to either hypothesis. Nevertheless, the relatively small temperature coefficients in our study have also been found in studies of freshwater crustacean zooplankton (de Castro and Gaedke, 2008) and of insects (Irlich et al., 2009).

\subsection{Test of the MTE - body size effects}

Weight-specific growth rate was negatively correlated with body size (Table 1), which is also a general finding for 
Table 4. Results of multivariate GLM based on stepwise selection procedure. $g$ : weight-specific growth rate (day ${ }^{-1}$ ); $\beta_{1}, \beta_{2}$, and $\beta_{3}$ : coefficients of the corresponding variables; $W_{0}$ : body size (carbon weight, $\left.\mu \mathrm{g}\right) ; T$ : temperature $(\mathrm{K})$; taxa: the categorical variable of taxa (including 7 taxa in the $100-150 \mu \mathrm{m}$ size fraction and 3 taxa in the $50-80 \mu \mathrm{m}$ size fraction); season represents the categorical variable of season (spring, summer, and winter); and $\varepsilon$ : error term. Model 3 is the final significant model. The current variable represents the significant variable already existing in the model, and the add-in variable represents the next selected variable into the model during the stepwise procedure. Note that the current variable is identical to the add-in variable in previous model.

\begin{tabular}{|c|c|c|c|c|c|c|}
\hline$F$ value & $r^{2}$ & $p$ value & $\begin{array}{l}\text { Current } \\
\text { variable }\end{array}$ & $\begin{array}{r}p \text { value of } \\
\text { current variable }\end{array}$ & $\begin{array}{l}\text { Add-in } \\
\text { variable }\end{array}$ & $\begin{array}{r}p \text { value of } \\
\text { add-in variable }\end{array}$ \\
\hline \multicolumn{7}{|c|}{ Model step 1: $\ln (g)=\beta_{2} \ln \left(W_{0}\right)+\varepsilon$} \\
\hline 49.486 & 0.205 & $<0.01$ & $\ln \left(W_{0}\right)$ & $<0.01$ & $\frac{1}{T}$ & $<0.01$ \\
\hline \multicolumn{7}{|c|}{ Model step 2: $\ln (g)=\frac{\beta_{1}}{T}+\beta_{2} \ln \left(W_{0}\right)+\varepsilon$} \\
\hline 31.793 & 0.247 & $<0.01$ & $\frac{1}{T}$ & $<0.01$ & $\operatorname{taxa}$ & $<0.01$ \\
\hline \multicolumn{7}{|c|}{ Model step 3: $\ln (g)=\frac{\beta_{1}}{T}+\beta_{2} \ln \left(W_{0}\right)+\beta_{3} \times \operatorname{taxa}+\varepsilon$} \\
\hline 25.647 & 0.282 & $<0.01$ & $\operatorname{tax} a$ & $<0.01$ & season & 0.46 \\
\hline
\end{tabular}

Table 5. Coefficients of body size $\left(a_{1}^{\prime}\right)$ from ordinary least squares (OLS) regression according to the function $g^{\prime}=a_{0}^{\prime}+a_{1}^{\prime} \ln \left(W_{0}\right)$, in comparison with the coefficients of body size calculated from major axis (MA) regression and from standardized major axis (SMA) regression. Values in parentheses: bootstrap estimation of standard error of coefficients; $g^{\prime}$ : temperature-corrected weight-specific growth rate, where $g^{\prime}=\ln (g)+\left(E / k_{B}\right) T^{-1} ; g$ : weight-specific growth rate $\left(\right.$ day $\left.^{-1}\right) ; W_{0}$ : body size (carbon weight, $\left.\mu \mathrm{g}\right) ; T$ : temperature $(\mathrm{K}) ; E$ : activation energy $(\mathrm{eV}) ; k_{\mathrm{B}}$ : Boltzmann's constant $\left(8.62 \times 10^{-5} \mathrm{eV} \mathrm{K}^{-1}\right)$. For SMA regression, $g^{\prime}$ and $\ln \left(W_{0}\right)$ were standardized before analyses. Expected value represents the theoretical value according to MTE (Brown et al., 2004).

\begin{tabular}{lrrr}
\hline & $a_{1}^{\prime}(\mathrm{OLS})$ & $a_{1}^{\prime}(\mathrm{MA})$ & $a_{1}^{\prime}(\mathrm{SMA})$ \\
\hline $50-80 \mu \mathrm{m}$ & $-0.96( \pm 0.32)$ & $-0.39( \pm 0.14)$ & $-0.39( \pm 0.13)$ \\
$100-150 \mu \mathrm{m}$ & $-0.46( \pm 0.26)$ & $-0.22( \pm 0.11)$ & $-0.22( \pm 0.10)$ \\
\hline Broadcaster & $-0.29( \pm 0.17)$ & $-0.32( \pm 0.16)$ & $-0.32( \pm 0.16)$ \\
Sac-spawner & $-0.53( \pm 0.08)$ & $-0.54( \pm 0.07)$ & $-0.54( \pm 0.06)$ \\
\hline All & $-0.48( \pm 0.07)$ & $-0.49( \pm 0.07)$ & $-0.49( \pm 0.07)$ \\
Expected value & -0.25 & -0.25 & -0.25 \\
\hline
\end{tabular}

copepods (e.g., Paffenhöfer, 1976; McKinnon and Duggan, 2003). However, the estimated coefficients for body size deviated from the predictions of MTE (Table 1). The deviation also occurred when 50-80 $\mu \mathrm{m}$ and sac-spawner groups were analyzed (Table 1). Since gaining popularity through ecosystem function studies, many studies have attempted to test or find evidence of the global predictive value of the MTE, especially the quarter-scaling of metabolic rates (e.g., Duncan et al., 2007; Seibel, 2007; Reiss and Schmid-Araya, 2010). Most of the studies have demonstrated that weight-specific metabolic rates scale with body size with an exponent of -0.25 as predicted by the MTE (e.g., Peters, 1983; Reiss and Schmid-Araya, 2010), or a higher (less negative) value (e.g., de Castro and Gaedke, 2008). In contrast, we found that our weight-specific growth rate scaled with body size by a much smaller (more negative: -0.51 , Table 1 ) value than -0.25 .

One intrinsic problem may lie in the overall range of body size in our data set. As demonstrated by Tilman et al. (2004), the variance of metabolic rates explained by body size decreases when the total range of body size decreases. According to their analysis, only $2-20 \%$ variance was explained by body size when there was only a 10 -fold range of body size. Indeed, in our data set (about $10^{1.5}$-fold range of body size due to our size-fraction design), the proportion of variance explained by body size was $\sim 21.0 \%$. This constraint might help explain why the body size dependence of copepod growth rates was not well described by the MTE for some groups.

Another consideration is the regression method in use. Instead of ordinary least squares (OLS) regression, (standardized) major axis (SMA or MA) regression has been recommended when both variables had comparable variances (Quinn and Keough 2002). To check this possibility, we independently analyzed our data in the form of "temperaturecorrected weight-specific growth rate" in relation to "body size" by OLS, MA and SMA regression. There was an improvement in the $50-80 \mu \mathrm{m}$ group (from $-0.96 \pm 0.32$ to $-0.39 \pm 0.14$, Table 5), while the size coefficients estimated for the other groups remain similar among regression methods (Table 5). The size-class-specific differences may be related to issues associated with overall body-size range: the size ranges of the size-fraction groups might have also been so narrow that the slope estimation was prone to experimental error of body size measurement. This result might point to an inadequacy with simple OLS regression against the MTE-based prediction. Nevertheless, Carroll and Ruppert (1996) argued that there might be an over-correction for MA regression. 
Additionally, our results demonstrated differences between taxonomic groups (Table 1). Seibel (2007) demonstrated that if the differences in the normalized constant $\left(a_{0}\right)$ and/or slope $\left(a_{2}\right)$ among groups were large, the generality of MTE might diminish. Previous studies also emphasized the importance of phylogenetic structure (e.g., Ives and Zhu, 2006; Duncan et al., 2007; Fagan et al., 2010; Ehnes et al., 2011). However, analytic methods that incorporate both phylogenetic correction and major axis regression are still lacking (O'Connor et al., 2007).

Furthermore, there are developed models that might explain the deviation from the MTE-based prediction: demandsupply model (Banavar et al., 2002), cell size model (Kozlowski et al., 2003), cost-of-transport (COT) model (Seibel, 2007), etc. Banavar et al. (2002) proposed a demand-supply model and explained that a more negative scaling of body size could arise when the tissues in need of additional supply (e.g., function-specialized tissues) were added such as during ontogenetic development or when the analysis was made among closely related species. However, their demand-supply model predicted the scaling to vary only in a range of -0.33 to -0.25 (Banavar et al., 2002), which was still outside the range of the scaling values observed in our data $(-0.51 \pm 0.07)$, providing only a partial explanation of the deviation.

According to the MTE with an underlying nutrient supply network model, phylogenetic differences exert an influence only on the normalized constant $\left(a_{0}\right)$ but not on the slope of body size $\left(a_{2}\right)$ (Savage et al., 2004). In contrast, the cell size model (Kozlowski et al., 2003) predicts a constant slope for body size $\left(a_{2}\right)$ only for the widest interspecific level; for intraspecific or intermediate resolution, $a_{2}$ would range from -0.33 to 0 . This broad $a_{2}$ range was attributed to different fractions of cell number increase (isometric, $a_{2}=0$ ) or cell size increase $\left(a_{2}=-0.33\right)$ that account for changes in body size, as demonstrated by Chown et al. (2007). Therefore, the cell size model might account for some deviation of our size coefficient estimates, as the taxonomic resolution used in this study is low.

On a group-specific basis, we found that the coefficients of body size were smaller (more negative) in the $50-80 \mu \mathrm{m}$ group than the 100-150 $\mu \mathrm{m}$ group (Table 1). There is an expectation (West et al., 1997) of a shallower (less negative) slope for smaller copepods because of a higher proportion of cubic-branching vessels (relatively scale-invariant) in smaller organisms. However, we have found the opposite pattern in this study. We also found that the body size coefficients were more negative in the sac-spawner group than the broadcaster group (Table 1). Our results are consistent with the observations of Hopcroft et al. (1998), but contrast with the observations of Hirst and Bunker (2003). Seibel (2007) suggests that different metabolic scaling in two types of squid occurs due to different locomotory costs, and this consideration can be applied in two motility types of copepods. According to the cost-of-transport (COT) model, the group with less efficiency of motility and higher metabolic cost (i.e., "broadcaster" group here; Almeda et al., 2010) should have lower (more negative) scaling in metabolic rate (Seibel, 2007). However, our findings were opposite to the COT prediction. Nevertheless, we demonstrate that the deviation from MTE could possibly be attributed to both the differences in taxonomy and analytical method in use, and that speciesspecific examination and improved analytical methods may help to resolve these issues.

\subsection{Test of the MTE - food availability}

Alternatively, the deviation from the growth rate relationship described by the MTE may be due to other variables and processes not explicitly addressed by the MTE (Brown et al., 2004). One of the most important factors is food availability. Many studies have presented evidence for foodlimited copepod growth rates (e.g., Paffenhöfer, 1976; Kimmerer and McKinnon, 1987; McKinnon and Ayukai, 1996; Gould and Kimmerer, 2010). Our finding of a significant correlation between $\ln$ (growth rate) of broadcast-spawning copepods and chlorophyll $a$ concentration (by Monod function before any correction, Fig. E1) is in agreement with the generalization that broadcasters are relatively herbivorous (Mauchline, 1998), although more contemporary studies describe the mixed diets for small copepods (e.g., Turner, 2004). Furthermore, the coefficient estimates of the MTE regression for the broadcaster group (Table 1) were closer to theoretical values $\left(E=0.6-0.7, a_{2}=-0.25\right)$ when we eliminated the "food-limited" growth (i.e., before elimination: $E=0.46 \pm 0.31, a_{2}=-0.31 \pm 0.12$; after elimination: $\left.E=0.67 \pm 0.42, a_{2}=-0.27 \pm 0.18\right)$. This observation indicates that the copepod communities in our study area are at least sometimes exposed to food limiting conditions. To examine this possibility more fully, we constructed different nonlinear models explicitly incorporating food availability (Tables 2, 3). In these models, we analyzed growth rate in relation to temperature, body size and chlorophyll $a$ concentration. The best model (lowest AIC) links growth rate with temperature, body size and Monod function (or logistic form) of chlorophyll $a$ concentration, regardless of whether "food-limited" growth values were eliminated (Table 2) or not (Table 3). Such a response suggests an important role for phytoplankton food in explaining the variation of growth rate. However, the coefficient estimates for temperature and body size were altered and still deviated from the theoretical values when food concentration was included in the model (Tables 2, 3). Indeed, Dzierzbicka-Glowacka (2004) demonstrated that copepod growth was not correlated with temperature when food concentrations dropped below the threshold for maximal growth rate. That is, the relationship between copepod growth and temperature or body size might be also influenced by food availability. For example, a negative or nil effect of temperature on growth rate could be observed when the food requirements increase with temperature (as 
suggested by Vidal, 1980). This is contrary to the statement of the MTE that the factors other than temperature and body size should only affect the constant term $\left(a_{0}\right.$; Gillooly et al., 2006).

Furthermore, detailed information on food (e.g., preference, differential response and non-phytoplankton food) might also play a significant role in determining variation of in situ growth rates and deserves further consideration. Substantially, we note one of the caveats of our analysis is that copepods can utilize various types of food in addition to phytoplankton (as listed in Table A1, e.g., microzooplankton, Turner, 2004). Non-phytoplankton foods could obscure the food effects (chlorophyll $a$ concentration) analyzed in this study, and it may have influenced our ability to accurately test the assumption of MTE that no food limitation was met. However, since the biomass of most microbial components (sampled as POC) still has a strong correlation to chlorophyll $a$ concentration (Legendre and Michaud, 1999), chlorophyll $a$ concentration perhaps could still be interpreted as a proxy or index of food availability rather than just phytoplankton. We also note that by using the $50 \mu \mathrm{m}$ filtrate of seawater for incubation water and the food source, we did run the risk of removing large food particles. This aspect of our experimental design was determined according our lower limit size fraction (i.e., 50-80 $\mu \mathrm{m}$ ). In addition, it has been reported that copepods generally have a 1- to 2-order (i.e., 10100 times) length difference with their prey food (Berggreen et al. 1988); therefore, the small copepods in our incubations (50-80 and 100-150 $\mu \mathrm{m}$ in length) were likely utilizing food particles less than the $50 \mu \mathrm{m}$ as main food resources, and thus our design may not have serious problems of food exclusion. In our experimental design, the incubation tanks were kept dark to reduce the possibility of growth of primary producers (and thus the confounding bottom-up effect); as such, the total chlorophyll $a$ concentration in the cubitainers could be simply estimated by initial concentration. However, we still note our assumption of no container effect along incubation. Furthermore, the elemental composition of food (e.g., $\mathrm{N}: \mathrm{C}$ ) is thought to be positively related with growth rate (Touratier et al., 1999; Jones et al., 2002). The phosphorus content of zooplankton itself has been found to correlate with their growth (Gillooly et al., 2002). However, the relative importance of these "quality" factors in influencing variation of in situ growth rates is still unclear.

\subsection{Spatio-temporal patterns and taxonomic differences}

Seasonal differences in growth rates were not clear in this study when considering all stations (Table 4). We do note the size fractions used in this research might still miss some representative species in different seasons, and that we could not distinguish the species-specific patterns due to our relatively low resolution of identification. However, we also note that the biomass of copepod communities in the East China Sea is dominated by small-bodied animals (e.g., Lo et al., 2004), which were well represented in our incubations. When focusing on a single station (station 9 in Fig. 1), we did find different numerical trends and variations of growth rate between calanoid and cyclopoid (Fig. 7). These results are consistent with studies noting that cyclopoids are able to maintain a relatively stable population and become increasingly dominant under oligotrophic conditions due to their wide distribution, low metabolic rates, low food requirement, and wide array of prey preferences (Almeda et al., 2010).

With respect to spatial differences, we found no clear pattern of growth rate from coast to offshore ("space" term not selected in multivariate GLM stepwise selection, Table 4). Our finding was similar to that of Miyashita et al. (2009) in the subtropical region. We found only marginally (but nonsignificant) higher growth rates in "high salinity, high chlorophyll" stations (group B; Fig. F1). This result is comparable to that of Arendt et al. (2010), who found that the production of copepods was higher in offshore areas. Additionally, our results suggested potential effects of salinity and phytoplankton biomass on growth rates. While the effect of phytoplankton biomass has already been demonstrated by previous studies (e.g., Vidal, 1980), very few studies have documented a potential effect of salinity (e.g., Chinnery and Williams, 2004; Beyrend-Dur et al., 2011). Beyrend-Dur et al. (2011) and Avila et al. (2011) attributed lower growth rates under conditions of salinity stress because more energy must be allocated for osmoregulation. This might have been the case in our "low salinity" groups. However, we did not analyze this issue further as the spatial difference was not clear.

Our observations of higher growth rates for calanoids relative to cyclopoids (Fig. 5) were consistent with previous studies noting similar taxonomic differences (Hopcroft et al., 1998; Hopcroft and Roff, 1998; Kiørboe and Sabatini, 1995). Moreover, the growth rates of the 50-80 $\mu \mathrm{m}$ group (mainly nauplii) were higher than that of the $100-150 \mu \mathrm{m}$ group (mainly copepodites) (Fig. 5), similar to the finding of Kiørboe and Sabatini (1995).

\subsection{Growth rate measurements compared with other empirical model predictions}

We found the weight-specific growth rates of copepods in our study area were within the range of reported values in previous studies (Kimmerer et al., 2007). However, our growth rate measurements differ from some of the estimates using empirical models (Fig. 8; ANOVA, $F=274.29, p<$ 0.01). Post hoc comparison revealed that the growth rate predictions from the Huntley and Lopez (1992), Hirst and Sheader (1997) and Hirst and Bunker (2003) models were all significantly higher than our measurements, while the growth rate predicted by Hirst and Lampitt (1998) were significantly lower than our measurements. The Huntley and Lopez (1992) model relies entirely on temperature and has been criticized as an oversimplification that often overestimates growth rates 


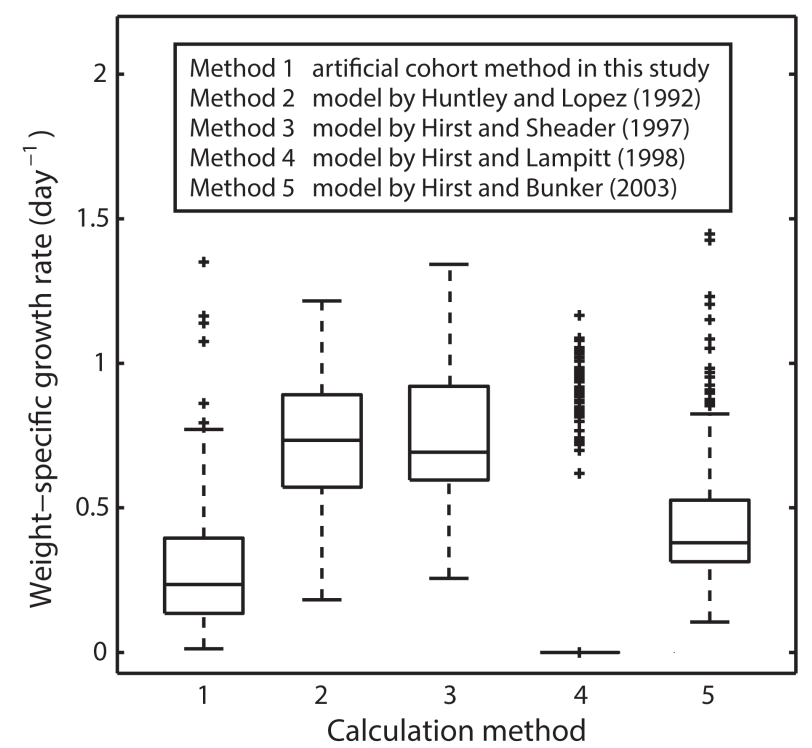

Fig. 8. Measured weight-specific growth rates compared to modelderived growth rates. The boxplots for each taxon indicate the values of medians, 25th and 75th percentiles, $95 \%$ confidence intervals (whiskers), and outliers (crosses). The confidence interval for method 4 was narrow and most of the calculated values were close to zero.

(e.g., Kleppel et al., 1996). Estimates from the other three models (Hirst and Sheader, 1997; Hirst and Lampitt, 1998; Hirst and Bunker, 2003) were also susceptible to bias attributable to food limitation rather than low temperature (Madsen et al., 2008). In addition, the relation between temperature and growth rate has often been described using an Arrhenius relationship (Brown et al., 2004) or at least curvilinear form (Almeda et al., 2010), contrary to the linear function assumed in those empirical models (e.g., Hirst and Bunker, 2003). According to the nature of those curvilinear functions, the increase of growth rate will follow an asymptotical fashion along with the increase in temperature. As a consequence, the growth rates tend to be overestimated in those empirical models when temperature is relatively high (Huntley and Lopez, 1992; Hirst and Sheader, 1997; Hirst and Bunker, 2003). The cause of underestimation from Hirst and Lampitt (1998) is because the temperature coefficient was negative for some copepod groups in their model, contrary to other models. This over-/underestimation likely occurred in the case of our study since our temperature range $\left(24.85 \pm 3.44^{\circ}\right)$ was close to the upper boundary of the empirical data-derived models (Huntley and Lopez,

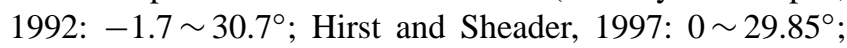
Hirst and Lampitt, 1998: $0 \sim 29^{\circ}$; Hirst and Bunker, 2003: $-2.3 \sim 34^{\circ}$ ). The discrepancy among field data and the empirical model predictions was also reported by other studies (e.g., Madsen et al., 2008).

\section{Conclusions}

In conclusion, the results of our study and analyses suggest that the MTE can be used to qualitatively describe variation of growth rates of copepod communities in the East China Sea; however, the scaling coefficients of temperature and body size deviate from predictions. The effects of food availability, regression method, and taxon-specific growth patterns should be considered when applying the MTE to predict growth rates of copepods. Further investigation is encouraged to clarify patterns of growth for entire copepod communities. Through a better understanding of growth rates, we could improve our knowledge of the production and thus the contribution of copepod communities in the East China Sea.

\section{Supplementary material related to this article is available online at: http://www.biogeosciences.net/10/ 1877/2013/bg-10-1877-2013-supplement.pdf.}

Acknowledgements. We acknowledge the assistance provided by the crews of R/V Ocean Researcher I and R/V Ocean Researcher II, Taiwan. Wei-Hsuan Teng and Yu-Ching Lee helped field sampling and experiments. Comments from Tai-Sheng Chiu, Carmen GarcíaComas, Chang-Feng Dai, Ryuji Machida, Takeshi Miki, and Chang-tai Shih greatly improved this work. This study was supported by National Taiwan University and National Science Council of Taiwan.

Edited by: T. Kobari

\section{References}

Almeda, R., Calbet, A., Alcaraz, M., Yebra, L., and Saiz, E.: Effects of temperature and food concentration on the survival, development and growth rates of naupliar stages of Oithona davisae (Copepoda, Cyclopoida), Mar. Ecol. Prog. Ser., 410, 97-109, 2010.

Arendt, K. E., Nielsen, T. G., Rysgaard, S., and Tönnesson, K.: Differences in plankton community structure along the Godthåbsfjord, from the Greenland Ice Sheet to offshore waters, Mar. Ecol. Prog. Ser., 401, 49-62, 2010.

Atkinson, A.: Subantarctic copepods in an oceanic, low chlorophyll environment: ciliate predation, food selectivity and impact on prey populations, Mar. Ecol. Prog. Ser., 130, 85-96, 1996.

Atkinson, D.: Temperature and organism size: a biological law for ectotherms?, Adv. Ecol. Res., 25, 1-58, 1994.

Avila, T. R., de Souza Machado, A. A., and Bianchini, A.: Chitobiase of planktonic crustaceans from South Atlantic coast (Southern Brazil): Characterization and in?uence of abiotic parameters on enzyme activity, J. Exp. Mar. Biol. Ecol., 407, 323-329, 2011.

Banavar, J. R., Damuth, J., Maritan, A., and Rinaldo, A.: Supplydemand balance and metabolic scaling, P. Natl. Acad. Sci. USA, 99, 10506-10509, 2002. 
Beers, J. R.: Studies on the chemical composition of the major zooplankton groups in the Sargasso Sea off Bermuda, Limnol. Oceanogr., 11, 520-528, 1966.

Berggreen, U., Hansen, B., and Kiørboe, T.: Food size spectra, ingestion and growth of the copepod Acartia tonsa during development: implications for determination of copepod production, Mar. Biol., 99, 341-352, 1988.

Besiktepe, S. and Dam, H. G.: Coupling of ingestion and defecation as a function of diet in the calanoid copepod Acartia tonsa, Mar. Ecol. Prog. Ser., 229, 151-164, 2002.

Beyrend-Dur, D., Kumar, R., Rao, T. R., Souissi, S., Cheng, S. H., and Hwang, J. H.: Demographic parameters of adults of Pseudodiaptomus annandalei: temperature-salinity and generation effects, J. Exp. Mar. Biol. Ecol., 404, 1-14, 2011.

Brown, J. H., Gillooly, J. F., Allen, A. P., Savage, V. M., and West, G. B.: Toward a metabolic theory of ecology, Ecology, 85, 17711789, 2004.

Calbet, A., Trepat, I., and Arin, L.: Naupliar growth versus egg production in the calanoid copepod Centropages typicus, J. Plankton Res., 22, 1393-1402, 2000.

Carroll, R. J. and Ruppert, D.: The use and misuse of orthogonal regression in linear errors-in-variables models, American Statistician, 50, 1-6, 1996.

Chen, M. R., Ka, S., and Hwang, J. S.: Diet of the copepod Calanus sinicus Brodsky, 1962 (Copepoda, Calanoida, Calanidae) in northern coastal waters of Taiwan during the northeast monsoon period, Crustaceana, 83, 851-864, 2010.

Chinnery, F. E. and Williams, J. A.: The influence of temperature and salinity on Acartia (Copepoda: Calanoida) nauplii survival, Mar. Biol., 145, 733-738, 2004.

Chown, S. L., Marais, E., Terblanche, J. S., Klok, C. J., Lighton, J. R. B., and Blackburn, T. M.: Scaling of insect metabolic rate in inconsistent with the nutrient supply network model, Funct. Ecol., 21, 282-290, 2007.

Clarke, A.: Is there a universal temperature dependence of metabolism?, Funct. Ecol., 18, 252-256, 2004.

Conover, R. J.: Assimilation of organic matter by zooplankton, Limnol. Oceanogr., 11, 338-345, 1966.

Cudeck, R. and Browne, M. W.: Cross-validation of covariance structures, Multivar. Behav. Res., 47, 147-167, 1983

de Castro, F. and Gaedke, U.: The metabolism of lake plankton does not support the metabolic theory of ecology, Oikos, 117, 12181226, 2008.

Duncan, R. P., Forsyth, D. M., and Hone, J.: Testing the metabolic theory of ecology: allometric scaling exponents in mammals, Ecology, 88, 324-333, 2007.

Dzierzbicka-Glowacka, L.: Growth and development of copepodite stages of Pseudocalanus spp., J. Plankton Res., 26, 49-60, 2004.

Ehnes, R. B., Rall, B. C., and Brose, U.: Phylogenetic grouping, curvature and metabolic scaling in terrestrial invertebrates, Ecol. Lett., 14, 993-1000, 2011.

Fagan, W. F., Lynch, H. J., and Noon, B. R.: Pitfalls and challenges of estimating population growth rate from empirical data: consequences for allometric scaling relations, Oikos, 119, 455-464, 2010.

Finlay, K. and Roff, J. C.: Ontogenetic growth rate responses of temperate marine copepods to chlorophyll concentration and light, Mar. Ecol. Prog. Ser., 313, 145-156, 2006.
Gillooly, J. F., Brown, J. H., West, G. B., Savage, V. M., and Charnov, E. L.: Effects of size and temperature on metabolic rate, Science, 293, 2248-2251, 2001.

Gillooly, J. F., Charnov, E. L., West, G. B., Savage, V. M., and Brown, J. H.: Effects of size and temperature on developmental time, Nature, 417, 70-73, 2002.

Gillooly, J. F., Allen, A. P., Savage, V. M., Charnov, E. L., West, G. B., and Brown, J. H.: Response to Clarke and Fraser: effects of temperature on metabolic rate, Funct. Ecol., 20, 400-404, 2006.

Gong, G. C., Wen, Y. H., Wang, B. W., and Liu, G. J.: Seasonal variation of chlorophyll $a$ concentration, primary production and environment conditions in the East China Sea, Deep-Sea Res. Pt. II, 50, 1219-1236, 2003.

Gould, A. L. and Kimmerer, W. J.: Development, growth, and reproduction of the cyclopoid copepod Limnoithona tetraspina in the upper San Francisco Estuary, Mar. Ecol. Prog. Ser., 412, 163177, 2010.

Harris, R. P. and Paffenhöfer, G. A.: Feeding, growth and reproduction of the marine planktonic copepod Temora longicornis Müller, J. Mar. Biol. Assoc. UK, 56, 675-690, 1976.

Hirst, A. G. and Bunker, A. J.: Growth of marine planktonic copepods: Global rates and patterns in relation to chlorophyll $a$, temperature, and body weight, Limnol. Oceanogr., 48, 1988-2010, 2003.

Hirst, A. G. and Lampitt, R. S.: Towards a global model of in situ weight-specific growth in marine planktonic copepods, Mar. Biol., 132, 247-257, 1998.

Hirst, A. G. and Sheader, M.: Are in situ weight-specific growth rates body-size independent in marine planktonic copepods?, A re-analysis of the global syntheses and a new empirical model, Mar. Ecol. Prog. Ser., 154, 155-165, 1997.

Hopcroft, R. R. and Roff, J. C.: Zooplankton growth rates: the influence of size in nauplii of tropical marine copepods, Mar. Biol., 132, 87-96, 1998.

Hopcroft, R. R., Roff, J. C., Webber, M. K., and Witt, J. D. S.: Zooplankton growth rates: the influence of size and resources in tropical marine copepodites, Mar. Biol., 132, 67-77, 1998.

Huntley, M. E. and Lopez, M. M. G.: Temperature-dependent production of marine copepods: a global synthesis, Am. Nat., 140, 201-242, 1992.

Ianora, A., Poulet, S. A., and Miralto, A.: The effects of diatoms on copepod reproduction: a review, Phycologia, 42, 351-363, 2003.

Irigoien, X., Harris, R., Verheye, H. M., Joly, P., Runge, J., Starr, M., Pond, D., Campbell, R., Shreeve, R., Ward, P., Smith, A. N., Dam, H. G., Peterson, W., Tirelli, V., Koski, M., Smith, T., Harbour, D., and Davidson, R.: Copepod hatching success in marine ecosystems with high diatom concentrations, Nature, 419, 387389, 2002.

Irlich, U. M., Terblanche, J. S., Blackburn, T. M., and Chown, S. L.: Insect rate-temperature relationships: environmental variation and the metabolic theory of ecology, Am. Nat., 174, 819-835, 2009.

Ives, A. R. and Zhu, J.: Statistics for correlated data: phylogenies, space, and time, Ecol. Appl., 16, 20-32, 2006.

Jones, R. H., Flynn, K. J., and Anderson, T. R.: Effect of food quality on carbon and nitrogen growth efficiency in the copepod Acartia tonsa, Mar. Ecol. Prog. Ser., 235, 147-156, 2002.

Kimmerer, W. J. and McKinnon, A. D.: Growth, mortality and secondary production of the copepod Acartia tranteri in Westernport 
Bay, Australia, Limnol. Oceanogr., 32, 14-28, 1987.

Kimmerer, W. J., Hirst, A. G., Hopcroft, R. R., and McKinnon, A. D.: Estimating juvenile copepod growth rates: corrections, intercomparisons and recommendations, Mar. Ecol. Prog. Ser., 336, 187-202, 2007.

Kingsolver, J. G. and Huey, R. B.: Size, temperature, and fitness: three rules, Evol. Ecol. Res., 10, 251-268, 2008.

Kiørboe, T.: Population regulation and role of mesozooplankton in shaping marine pelagic food webs, Hydrobiologia, 363, 13-27, 1997.

Kiørboe, T. and Sabatini, M.: Scaling of fecundity, growth and development in marine planktonic copepods, Mar. Ecol. Prog. Ser., 120, 285-298, 1995.

Kleppel, G. S., Davis, C. S., and Carter, K.: Temperature and copepod growth in the sea: a comment on the temperature-dependent model of Huntley and Lopez, Am. Nat., 148, 397-406, 1996.

Kobari, T., Imamura, S., and Habano, A.: Growth rate of predominant copepods in Kagoshima Bay - estimation by artificial cohort method, Mem. Fac. Fish. Kagoshima Univ., 56, 45-54, 2007.

Kozlowski, J., Konarzewski, M., and Gawelczyk, A. T.: Cell size as a link between noncoding DNA and metabolic rate scaling, $\mathrm{P}$. Natl. Acad. Sci. USA, 100, 14080-14085, 2003.

Lan, Y. C., Lee, M. A., Chen, W. Y., Hsieh, F. J., Pan, J. Y., Liu, D. C., and Su, W. C.: Seasonal relationships between the copepod community and hydrographic conditions in the southern East China Sea, ICES J. Mar. Sci., 65, 462-468, 2008.

Landry, M. R.: Population dynamics of the planktonic marine copepod, Acartia clausi Giesbrecht, in a small temperate lagoon, University of Washington, Seattle, 1976.

Landry, M. R.: Predatory feeding behavior of the marine cyclopoid copepod Corycaeus anglicus, Mar. Biol., 85, 163-169, 1985.

Lawrence, S. G., Ahmad, A., and Azam, F.: Fate of particle-bound bacteria ingested by Calanus pacificus, Mar. Ecol. Prog. Ser., 97, 299-307, 1993.

Leandro, S. M., Tiselius, P., and Queriroga, H.: Growth and development of nauplii and copepodites of the estuarine copepods Acartia tonsa from southern Europe (Ria de Aveiro, Portugal) under saturating food concentration, Mar. Biol., 150, 121-129, 2006.

Legendre, L. and Michaud, J.: Chlorophyll $a$ to estimate the particulate organic carbon available as food to large zooplankton in the euphotic zone of oceans, J. Plankton Res., 21, 2067-2083, 1999.

Lin, K. Y., Sastri, A., and Hsieh, C. H.: An alternative kernel-based method for estimating copepod growth rates from multi-modal biomass distribution, Zool. Stud., in press, 2013.

Liu, H. and Hopcroft, R. R.: Growth and development of Neocalanus flemingeri/plumchrus in the northern Gulf of Alaska: validation of the artificial-cohort method in cold waters, J. Plankton Res., 28, 87-101, 2006a.

Liu, H. and Hopcroft, R. R.: Growth and development of Metridia pacifica (Copepoda : Calanoida) in the northern Gulf of Alaska, J. Plankton Res., 28, 769-781, 2006b

Lo, W. T., Shih, C. T., and Hwang, J. S.: Copepod assemblages and diel vertical migration in the East China Sea, North of Taiwan, Crustaceana, 77, 955-971, 2004.

Longhurst, A. R.: The structure and evolution of plankton communities, Prog. Oceanogr., 15, 1-35, 1985.

Madsen, S. D., Nielsen, T. G., and Hansen, B. W.: Annual population development and production by small copepods in Disko
Bay, western Greenland, Mar. Biol., 155, 63-77, 2008.

Mauchline, J., Blaxter, J. H. S., Southward, A. J., and Tyler, P. A.: The Biology of Calanoid Copepods, Elsevier Academic Press, San Diego, 710 pp., 1998.

McKinnon, A. D. and Ayukai, T.: Copepod egg production and food resources in Exmouth Gulf, Western Australia, Mar. Freshwater Res., 47, 595-603, 1996.

McKinnon, A. D. and Duggan, S.: Summer copepod production in subtropical waters adjacent to Australia's North West Cape, Mar. Biol., 143, 897-907, 2003.

McLaren, I. A.: Generation lengths of some temperate marine copepods: Estimation, prediction, and implications, J. Fish. Res. Board. Can., 35, 1330-1342, 1978.

Merrell, J. R. and Stoecker, D. K.: Differential grazing on protozoan microplankton by developmental stages of the calanoid copepod Eurytemora affinis Poppe, J. Plankton Res., 20, 289-304, 1998.

Miller, C. B., Johnson, J. K., and Heinle, D. R.: Growth rules in the marine copepod genus Acartia, Limnol. Oceanogr., 22, 326-335, 1977.

Miyashita, L. K., Júnior, M. D. M., and Lopes, R. M.: Estuarine and oceanic influences on copepod abundance and production of a subtropical coastal area, J. Plankton Res., 31, 815-826, 2009.

Mullin, M. M., Brook, E. R., and Steel, J. H. (Eds.): Growth and metabolism of two planktonic, marine copepods as influenced by temperature and type of food, in: Marine Food Chain, University of California Press, Great Britain, 74-95, 1997.

O’Connor, M. P., Agosta, S. J., Hansen, F., Kemp, S. J., Sieg, A. E., McNair, J. N., and Dunham, A. E.: Phylogeny, regression, and the allometry of physiological traits, Am. Nat., 170, 431-442, 2007.

Ohtsuka, S. and Kubo, N.: Larvaceans and their houses as important food for some pelagic copepods, Proceedings of the fourth International Conference on Copepods, 16-20 September 1990, Bull. Plankton Soc. Japan, Spec. Vol., 535-551, 1991.

Okasaki, Y., Noguchi, T., Nakata, H., and Nishiuchi, K.: Distribution and abundance of copepod nauplii in southern part of the East China Sea: implications for prey availability to jack mackerel Trachurus japonicus larvae, Fisheries Sci., 74, 1235-1244, 2008.

Paffenhöfer, G. A.: Feeding, growth and food conversion of the marine planktonic copepod Calanus helgolandicus, Limnol. Oceanogr., 21, 39-50, 1976

Paffenhöfer, G. A.: An assessment of the effects of diatoms on planktonic copepods, Mar. Ecol. Prog. Ser., 227, 305-310, 2002.

Paffenhöfer, G. A. and Harris, R. P.: Feeding, growth and reproduction of the marine planktonic copepod Pseudocalanus elongatus Boeck, J. Mar. Biol. Assoc. UK, 56, 327-344, 1976.

Peters, R. H.: Ecological implications of body size, Cambridge University Press, New York, 1983.

Peters, J., Renz, J., van Beusekom, J., Boersma, M., and Hagen, W.: Trophodynamics and seasonal cycle of the copepod Pseudocalanus acuspes in the Central Baltic Sea (Bornholm Basin): evidence from lipid composition, Mar. Biol., 149, 1417-1429, 2006.

Postel, L., Fock, H., Hagen, W.: Biomass and abundance, in: ICES Zooplankton Methodology Manual, edited by: Harris, R. P., Wiebe, P. H., Lenz, J., Skjoldal, H. R., and Huntley, M. E., Academic Press, London, 2000. 
Poulet, S. A., Ianora, A., Laabir, M., and Klein Breteler, W. C. M.: Towards the measurement of secondary production and recruitment in copepods, ICES J. Mar. Sci., 52, 359-368, 1995.

Quinn, G. P. and Keough, M. J.: Experimental Design and Data Analysis for Biologists, Cambridge University Press, New York, 2002.

Reinfelder, J. R. and Fisher, N. S.: The assimilation of elements ingested by marine copepods, Science, 251, 794-796, 1991.

Reiss, J. and Schmid-Araya, J. M.: Life history allometries and production of small fauna, Ecology, 91, 497-507, 2010.

Renz, J. and Hirche, J.: Life cycle of Pseudocalanus acuspes Giesbrecht (Copepoda, Calanoida) in the Central Baltic Sea: I. Seasonal and spatial distribution, Mar. Biol., 138, 567-580, 2006.

Richardson, A. J. and Verheye, H. M.: Growth rate of copepods in the southern Benguela upwelling system: the interplay between body size and food, Limnol. Oceanogr., 44, 382-392, 1999.

Runge, J. A. and Roff, J. C.: The measurement of growth and reproductive rates, in: ICES Zooplankton Methodology Manual, edited by: Harris, R., Wiebe, P., Lenz, J., Skjoldal, H. R., and Huntley, M., Academic Press, London, 2000.

Savage, V. M., Gillooly, J. F., Woodruff, W. H., West, G. B., Allen, A. P., Enquist, B. J., and Brown, J. H.: The predominance of quarter-power scaling in biology, Funct. Ecol., 18, 257-282, 2004.

Seber, G. A. F. and Hoboken, N. J.: Multivariate Observations, John Wiley \& Sons. Inc., Canada, 1984.

Seibel, B. A.: On the depth and scale of metabolic rate variation: scaling of oxygen consumption rates and enzymatic activity in the Class Cephalopoda (Mollusca), J. Exp. Biol., 210, 1-11, 2007.

Svetlichny, L. S.: Calculation of planktonic copepod biomass by means of coefficients of proportionality between volume and linear dimensions of the body, Ekol. Morya., 15, 46-58, 1983.

Tilman, D., HilleRisLambers, J., Harpole, S., Dybzinski, R., Fargione, J., Clark, C., and Lehman, C.: Does metabolic theory apply to community ecology? It's a matter of scale, Ecology, 85, 1797-1799, 2004.

Touratier, F., Legendre, L., and Vezina, A.: Model of copepod growth influenced by the food carbon:nitrogen ratio and concentration, under the hypothesis of strict homeostasis, J. Plankton Res., 21, 1111-1132, 1999.
Tseng, L. C., Souissi, S., Dahms, H. U., Chen, Q. C., and Hwang, J. S.: Copepod communities related to water masses in the southwest East China Sea, Helgol. Mar. Res., 62, 153-165, 2008.

Turner, J. T.: The importance of small planktonic copepods and their roles in pelagic marine food webs, Zool. Stud., 43, 255266, 2004.

Turner, J. T. and Roff, J. C.: Trophic levels and trophospecies in marine plankton: lessons from the microbial food web, Mar. Microb. Food Webs, 7, 225-248, 1993.

Turner, J. T., Tester, P. A., and Conley, W. J.: Zooplankton feeding ecology: predation by the marine cyclopoid copepod Corycaeus amazonicus F. Dahl upon natural prey, J. Exp. Mar. Biol. Ecol., 84, 191-202, 1984.

Uye, S. I.: Temperature-dependent development and growth of the planktonic copepod Paracalanus sp. in the laboratory, Proceedings of the fourth International Conference on Copepods, 1620 September 1990, Bull. Plankton Soc. Japan, Spec. Vol., 627636, 1991.

Uye, S. I.: Replacement of large copepods by small ones with eutrophication of embayments: cause and consequence, Hydrobiologia, 292/293, 513-519, 1994.

Vidal, J.: Physioecology of zooplankton. I. Effects of phytoplankton concentration, temperature, and body size on the growth rate of Calanus pacificus and Pseudocalanus sp., Mar. Biol., 56, 111134, 1980.

Wang, C. F., Hsu, M. H., and Liu, W. C.: Simulation of water quality and plankton dynamics in the Danshuei River estuary, Taiwan, J. Environ. Sci. Heal. A, 42, 933-953, 2007.

Wang, R. and Fan, C.: Copepods feeding activities and its contribution to downwards vertical flux of carbon in the East China Sea Oceanol. Limnol. Sin., 28, 579-587, 1997.

Webber, M. K. and Roff, J. C.: Annual biomass and production of the oceanic copepod community off Discovery Bay, Jamaica, Mar. Biol., 123, 481-495, 1995.

West, G. B., Brown, J. H., and Enquist, B. J.: A general model for the origin of allometric scaling laws in biology, Science, 276, 122-126, 1997. 